\title{
Antikanser Aktivite Gösterebilecek Yeni Heterohalkalı Bileşiklerin Sentezlenmesi ve Karakterizasyonu
}

\author{
Synthesis and Characterization of New Heterocyclic Derivatives as Possible \\ Anticancer Agents
}

\author{
Ömer Tahir GÜNKARA ${ }^{1}$ \\ ${ }^{1}$ Ylldız Teknik Üniversitesi, Fen-Edebiyat Fakültesi, Kimya Bölümü, Davutpaşa Kampüsü, Esenler/İstanbul
}

$\ddot{\mathrm{O} z}$

Son yıllarda kanser hastalığı üzerinde yapılan çalışmaların sayısı oldukça artmaktadır. Çeşitli kanser türlerine karşı etkili olabilecek anti-kanser ilaçlarının yenilerinin elde edilmesi için çeşitli çalışmalar yapılmaktadır. Bu çalışmada anti-kanser aktivite gösterebilecek yeni bisiklik schiff bazı türevleri sentezlenmiş ve sentezlenen yeni bileşiklerin yapıları IR, ${ }^{1} \mathrm{H}-\mathrm{NMR},{ }^{13} \mathrm{C}-\mathrm{NMR}$, GC-MS gibi spektroskopik yöntemlerle karakterize edilmiştir.

Anahtar Kelimeler: Anti-kanser aktivite, Anti-kanser ilaçlar, Heck reaksiyonları, Heterohalkalı bileşikler, Trisiklik imidler.

\begin{abstract}
The number of studies on cancer research has increased enormously during the last decade. Various studies have been carried out to obtain new anti-cancer drugs that may be effective against various types of cancer cells. In this work, new bicyclic schiff base derivatives were synthesized and all newly synthesized derivatives were structurally characterized by FTIR, ${ }^{1} \mathrm{H}-\mathrm{NMR},{ }^{13} \mathrm{C}-\mathrm{NMR}$ and GC/MS spectroscopic analyses.
\end{abstract}

Keywords: Anticancer activity, Anticancer drugs, Heck reactions, Heterocyclic compounds, Tricyclic imides

\section{GİRIȘ}

Kanser ölüm nedenleri arasında dünya genelinde ilk sıralarda yer alan karmaşık bir hastalıktır ve bu hastalık çağımızın hastalığı olmuştur. Kanser sebebi ile gerçekleşen ölümlerin artması sonucu bu konu üzerine yapılan çalışmalar son yıllarda oldukça artmıştır [1]. Anti-kanser aktivite gösterecek yeni moleküllerin sentezlenmesi ve ilaç olarak kullanılabilmesi günümüzde büyük önem taşımaktadır bu sebeple anti-kanser çalışmaları günümüzde oldukça yaygın bir şekilde yürütülmekte olan bir araştırma konusudur. Bu sebeple birçok araştırma grubu kanser hücrelerini tamamen ortadan kaldırabilecek yeni etken maddeler aramaktadır.

Günümüzde birçok kanser çeşidi bulunmaktadır ve bu türler için yeni anti-kanser ilaç arayışları devam etmektedir [2]. Doğal bileşikler, küçük organik moleküller gibi yeni ajanlar anti-kanser aktiviteleri sebebiyle bu kanser hücrelerine karşı öldürme güçleri denenmektedir.

Benzamid türevleri dikkat çekici derecede anti-bakteriyel, anti-fungal, anti-kanser ve antialerjik aktiviteler göstermektedir [3-10] ve hala aromatik ligandların sentezi için kullanılan en yaygın ara bileşiklerdendir. Schiff bazları da potansiyel anti-kanser ilaçlarıdır ve metal kompleksleri de aktivite göstermektedir [11-17] ve medikal alanda ilaç olarak kullanılmaktadirlar. 
İmid fonksiyonel grubu çeşitli önemli biyolojik aktif moleküllerde yer almaktadır. Literatür araştırmalarına göre, anti-kanser aktivite gösteren, DNA ile etkileşime girebilen, imid fonksiyonel grubuna sahip çeşitli moleküller belirlenmiştir. Örneğin fumaramidmycin, granulatimide, isogranulatimide ve rebeccamycin gibi moleküller imid fonksiyonel gruplarına sahiptir. Bu moleküllerin çeşitli anti-kanser, anti-mikrobiyal ve antienflamatuar aktivite gösterdiği rapor edilmiştir [18-22] (Şekil 1).
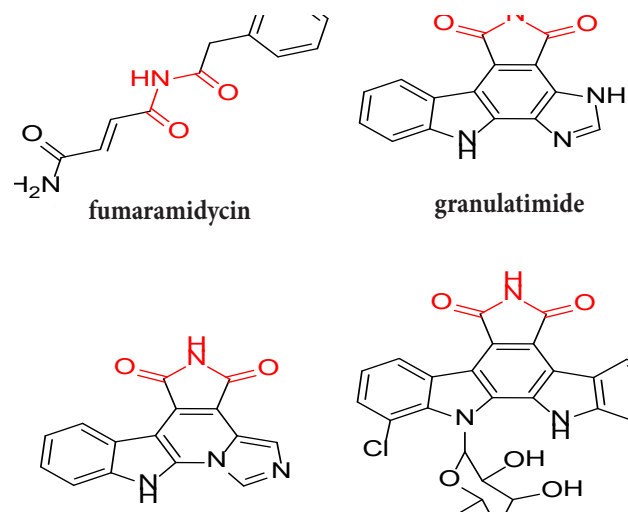

isogranulatimide

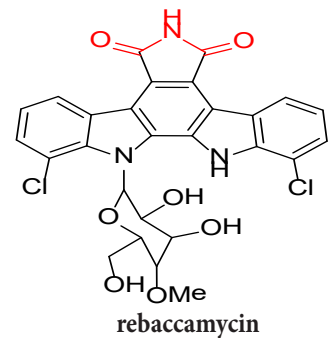

Şekil 1. Fumaramidycin, granulatimide, isogranulatimide ve rebaccamycin molekül yapıları

Trisiklik halkanın da biyolojik aktivitede önemli rolü bulunduğu bilinmektedir. Örneğin cantharidin ve norcantharidin bileşikleri anti-kanser aktivite gösteren bilinen iki bileşiktir.

Geleneksel Çin tıbbı potansiyel anti-kanser ajanlar için zengin bir kaynaktır. Özellikle Çin Bilister böceğinin (Şekil 2), Mylabris, kurutulmuş gövdesinden elde edilen Cantharidin ve Norcantharidin (Şekil 3) hücre döngüsü ilerlemesinde anahtar rollere sahip olan protein fosfataz 1 (PP1) ve 2A (PP2A) inhibitörüdür. Lösemi hücrelerinde, Cantharidin apoptozu p53 bağımlı bir mekanizma ile indükler.

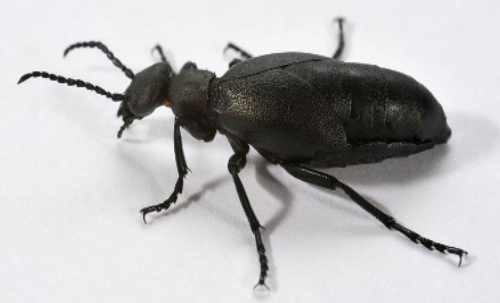

Şekil 2. Bilister böceği
Norcantharidin türevinin sentezi çok daha kolaydır ve toksisitesi daha düşüktür bu sebeple bu bileşik üzerine çalışmalar çok daha yaygındır [23-29].

Ayrıca bu iki bileşiğin imid türevleri de son yıllarda çok büyük ilgi görmektedir.

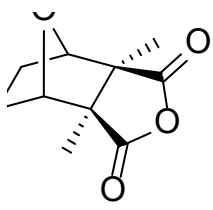

Cantharidin

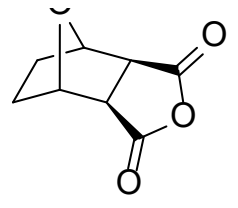

Norcantharidin
Şekil 3. Cantharidin ve Norcantharidin

Cantharidinin bir dizi kansere (lösemi, pankreas, kolon, serviks vb.) karş1 etkili olduğu kanıtlanmıştır ve birçok olumlu özelliği vardır [29]. Potansiyel toksisitelerine rağmen Cantharidin Çin tıbbında özellikle hepatoma ve özofageal karsinom tedavisinde 1264 yılından beri bir anti-kanser ajanı olarak kullanılmıştır. Norcantharidin, Cantharidin'in demetile edilmiş analoğu olup nefrotoksisite olmadan benzer anti-kanser aktivite sergiler [27].

Bu moleküllerin çeşitli anti-kanser aktiviteleri göstermeleri sebebiyle aromatik halka fonksiyonel grubuna sahip bisiklik imid türevlerinin sentezine yöneldik.

Yeni türevleri sentezlemek için indirgen Heck reaksiyonlarından yararlandık. Trifenilarsinin ligand olarak kullanıldığı [30-33] paladyum katalizli reaksiyonları gerçekleştirerek yeni anti-kanser aktivite gösterebilecek bisiklik imid türevleri sentezledik ve yapılarını çeşitli spektroskopik yöntemler kullanarak aydınlatmayı başardık.

\section{SONUÇ ve TARTIŞMA}

İlk olarak başlangıç maddesi olarak kullanılacak olan bisiklo[2.2.1]hept-5-en-endo-2,3-dikarboksilik anhidrit bileşiği (Bileşik-1) bilinen bir yöntem ile yüksek verimle elde edilmiştir [34]. Taze destillenmiş siklopentadien ve maleik anhidrit arasındaki Diels-Alder reaksiyonu sonucu Bileşik-1 sentezlenmiş (Şekil 4) ve sentezlenen bu bileşik etanol ile kristallendirilerek saflaştırılmıştır. 


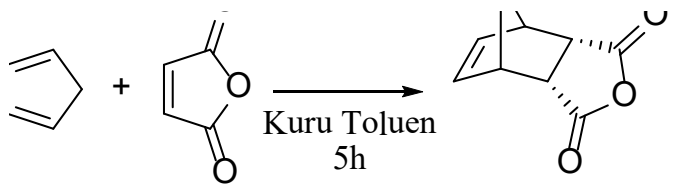

Bileşik 1

Şekil 4. Bileşik 1'in sentez yöntemi

Sentezlenen Bileşik 1'in yapısı, FTIR spektrumunun ve erime noktasının literatür verileri ile kıyaslanması ile doğrulanmıştır.

Elde edilen beyaz renkli kristallerden yola çıkarak $N$-aminobisiklo[2.2.1] hept-5-en-endo-2,3-dikarboksimid bileşiği (Bileşik-2) sentezlenmiş ve kristallendirme methodu ile saflaştırılmıştır [35] (Şekil 5).

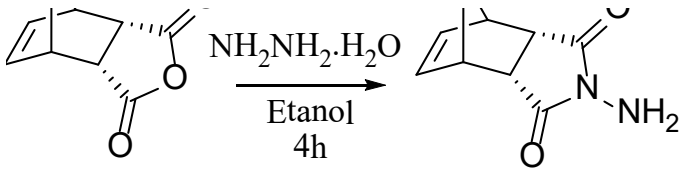

Bileşik 1

Bileşik 2

Sentezlenen bu bileşik saflaştırıldıktan sonra FTIR, ${ }^{1} \mathrm{H}-\mathrm{NMR},{ }^{13} \mathrm{C}-\mathrm{NMR}$ ve GC-MS gibi çeşitli spektroskopik yöntemlerle yapısı aydınlatılmıştır. FTIR spekturumu incelendiğinde Bileşik-2'nin FTIR spektrumunda yer alan - $\mathrm{NH}_{2}$ grubundan kaynaklanan $3300 \mathrm{~cm}^{-1}$ 'deki pikin kaybolduğu onun yerine $3013 \mathrm{~cm}^{-1}$, de aromatik halkadaki $=\mathrm{C}-\mathrm{H}$ bağının sebep olduğu gerilme bandının gözlemlendiği belirlenmiştir. ${ }^{1} \mathrm{H}-\mathrm{NMR}$ spektrumu incelendiğinde beklenen sayıda pikin beklenen alanlarda sinyal verdiği gözlenmektedir. 4 aromatik protona ait pikler sirasıyla 6.84 ve 7.68 ppmde doublet olarak gözlenmiştir. Metoksi grubuna ait pik ise singlet olarak 3.77 ppm'de sinyal vermektedir. Alkenik bağın hidrojenlerine ait sinyaller ise 6.14 ppm'de singlet olarak gözlenmiştir. 8.75 ppm'de gözlemlenen singlet pik schiff bazının $\mathrm{N}=\mathrm{CH}$ protonuna ait sinyaldir. ${ }^{1} \mathrm{H}-\mathrm{NMR}$ spektrumu yapıy1 doğrulamaktadır. ${ }^{13} \mathrm{C}-\mathrm{NMR}$ spektrumu da yapıyı doğrulamaktadır, beklenilen sayıda karbon atomu rezonans olmuştur.

Elde edilen Bileşik-3'ün indirgen Heck reaksiyonları gerçekleştirilmiştir. Reaksiyonlar kuru DMF içerisinde azot atmosferinde gerçekleştirilmiştir. Katalizör olarak $\mathrm{Pd}(\mathrm{OAc})_{2}$ kullanılmıştır. Ligand olarak $\mathrm{AsPh}_{3}$ kullanıldığında en yüksek verimler elde edilebilmiştir. 4-kloro-1-iyodobenzen kullanılarak gerçekleştirilen reaksiyon sonucu Bileşik 4 yüksek verimle elde edilmiştir (Şekil-7)

Literatürde yer alan yönteme göre sentezlenen Bileşik-2'nin yapısı FTIR spektrumu incelenerek doğrulanmıştır. Yapıda yer alan $-\mathrm{NH}_{2}$ grubuna ait $\mathrm{N}-\mathrm{H}$ bağ 1 gerilme band 1 $3300 \mathrm{~cm}^{-1}$ 'de gözlenmektedir. Erime noktası literatür verisi ile kıyaslanarak yapının doğruluğu teyit edilmiştir.

Saflaştırılan Bileşik-2'den yola çıkarak p-metoksibenzaldehit ile reaksiyonu sonucu Bileşik-3 yüksek verimle sentezlenmiştir. Elde edilen bu bileşik kolon kromatografisi yöntemi kullanılarak saflaştırılmıştır. Bileşik-2 ve p-metoksibenzaldehit kullanılarak bir schiff bazı oluşturulmuştur (Şekil 6).<smiles>NN1C(=O)[C@H]2C3C=CC(C3)[C@H]2C1=O</smiles>

Bileşik 2<smiles>C=Cc1ccc(OC)cc1</smiles>

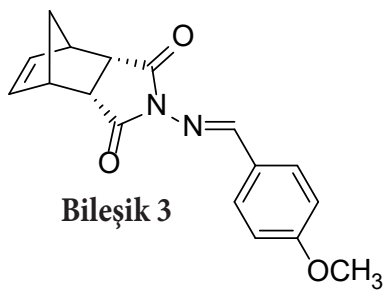

Şekil 6. Bileşik 3'ün sentez yöntemi
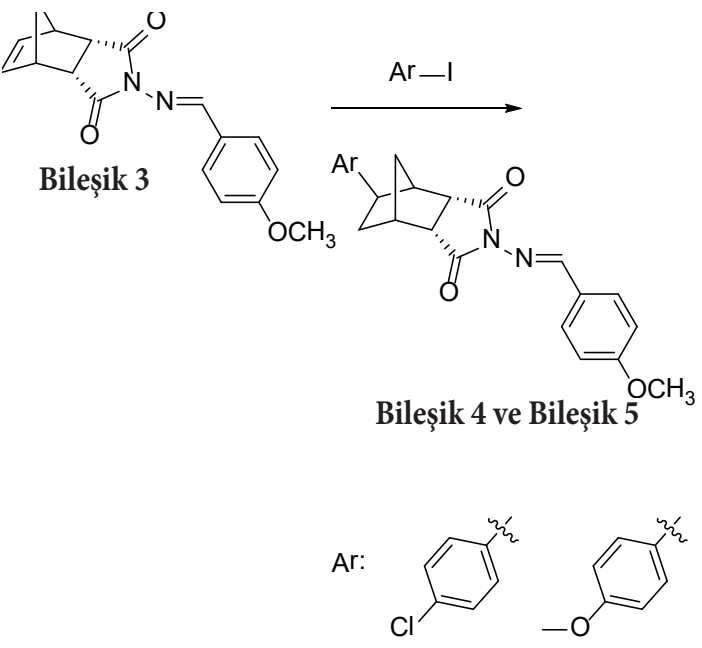

Bileșik 4 Bileşik 5

Bileşik 5'in sentezi için aril halojenür olarak 4-metoksi-1-iyodobenzen kullanılmıştır. Sentezlenen her iki bileşik de kolon kromatografisi yapılarak saflaştırılmıştır. Bileșik 4'ün ${ }^{1} \mathrm{H}-\mathrm{NMR}$ spektrumu incelendiğinde; Bileşik-3'te yer 
alan alkenik protonlara ait 6.14 ppmdeki singlet pikin gözlenmemiş onun yerinde dört tane daha aromatik protonun 7.24 ve 7.81 ppmde dublet olarak sinyal verdiği gözlemlenmiştir. Aynı şekilde Bileşik 5'in de ${ }^{1} \mathrm{H}-\mathrm{NMR}$ spektrumu incelendiğinde beklenilen sayıda pik gözlenmiştir. İki bileşiğin de ${ }^{13} \mathrm{C}$-NMR spektrumları yapı ile uyumludur.

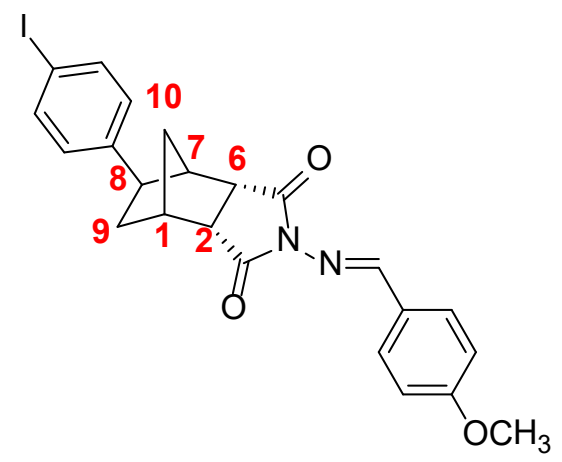

Bileşik 4

Şekil 8. Bileşik 4'ün molekül şekli

Bu schiff bazı türevi bisiklik bileşiklerin çeşitli kanser hücrelerine karşı anti-kanser aktivite göstermeleri beklenmektedir.

\section{DENEYSEL ÇALIŞMALAR}

\section{Genel Bilgi}

Tüm reaksiyonlar aksi belirtilmediği sürece azot atmosferinde yürütülmüştür. Reaksiyon ilerleyişi ince tabaka kromatografisi (TLC) ile izlenmiştir. TLC renklendirmesinde UV ışık ya da $\mathrm{KMnO}_{4}$ çözeltisi kullanılmıştır. Sentezlenen ürünler kolon kromatografisi kullanılarak saflaştırılmıştır, yürütücü sistemi olarak çeşitli oranlarda etil asetat/n-hekzan çözücü karışımı kullanılmıştır

IR spektrumları Perkin Elmer FT-IR cihazı ile ölçülmüştür. Erime noktaları Gallenkamp dijital termometre cihazı ile belirlenmiştir. NMR ölçümleri "Bruker--500 MHz NMR" cihazı ile yapılmıştır. TMS (tetrametilsilan) internal standart olarak kullanılmıştır. Tüm NMR ölçümleri $\mathrm{CDCl}_{3}$ çözücüsü içerisinde gerçekleştirilmiştir. Sinyaller çeşitli kısaltmalar kullanılarak raporlanmıştır. Kütle ölçümleri Agilent 6890N GC-System-5973 IMSD cihazı ile yapılmıştır.

\section{Sentez ve Karakterizasyon Çalış̧aları}

Bisiklo[2.2.1]hept-5-en-endo-2,3-dikarboksilik anhidrit bileşiğinin (Bileşik 1) Sentezi:

$1 \mathrm{~g}$ maleik anhidrit tartılarak çift boyunlu balon içerisine konuldu ve $5 \mathrm{~mL}$ susuz toluen içerisinde çözünmesi sağlandi. $0.85 \mathrm{~mL}$ taze destillenmiş siklopentadien reaksiyon ortamına damla damla ilave edildi. Reaksiyon karışımı azot atmosferinde, geri soğutucu altında beş saat kaynatıldı. Oluşan beyaz kristaller süzülerek reaksiyon ortamından ayrıldı ve soğuk eter ile yıkandı [34].

$N$-Aminobisiklo[2.2.1]hept-5-en-endo-2,3-dikarboksimid bileşiğinin (Bileşik 2) Sentezi:

$0.205 \mathrm{~g}$ Bileşik 1 tartılarak iki boyunlu balona alındı, $10 \mathrm{~mL}$ susuz etanol içerisinde çözünmesi sağlandı. $0.07 \mathrm{~mL}$ hidrazin hidrat reaksiyon ortamına tek seferde ilave edildi. Reaksiyon karışımı azot atmosferinde, geri soğutucu altında beş saat boyunca kaynatıldı. Reaksiyonun çözücüsü uçuruldu. Elde edilen katı kristallendirme yöntemi ile saflaşt1rrld1. Beyaz renkli kristaller elde edildi [35].

$\mathrm{N}$-(4-Metoksibenziliden)bisiklo[2.2.1] hept-5-en-endo-2,3-dikarboksimid bileşiğinin (Bileşik 3) Sentezi ve Spektral Verileri:

0.250 g Bileşik 2 tartılarak iki boyunlu balon içerisine konuldu, $10 \mathrm{~mL}$ susuz etanol içerisinde çözünmesi sağlandı. Azot atmosferi altında, $0.100 \mathrm{~mL}$ p-metoksibenzaldehit reaksiyon ortamina damla damla ilave edildi. Reaksiyon kar1\$̧ımı geri soğutucu altında altı saat boyunca kaynatıldı. Yapılan TLC çalışması sonucunda reaksiyon sonlandırıldı ve döner buharlaştırıcıda çözücüsü uçuruldu. Elde edilen ham ürün 2:1 etilasetat $/ n$-hekzan sisteminden kolon kromatografisi uygulanarak saflaştırıldı. Beyaz renkli kristaller elde edildi.

Beyaz renkli kristaller, en: $127.2-127.8^{\circ} \mathrm{C}$, Rf: $0.45(2: 1$ Etil asetat $/ n$-hekzan), verim \%50. FTIR (ATR): 3013 (aromatik $=\mathrm{C}-\mathrm{H}$ gerilimi), 2963, 2930, 2860 ve 2840 (alifatik $\mathrm{C}-\mathrm{H}$ gerilimleri), 1736 ve 1705 ( $\mathrm{C}=\mathrm{O}$ gerilimleri), 1598 ve $1570(\mathrm{C}=\mathrm{N}, \mathrm{C}=\mathrm{C}$ gerilimleri), 1510, 1455, 1442 ve 1386 (alifatik, düzlem içi C-H eğilimleri), 1256 (C-O gerilimi), 1186 ve 1167 (C-O-C gerilimi), 1028 (C-N salınımı), 720 (p-disubstitue aromatik halka düzlem dışı $\mathrm{C}-\mathrm{H}$ eğilimleri) $\mathrm{cm}^{-1}$. ${ }^{1} \mathrm{H}-\mathrm{NMR}\left(\mathrm{CDCl}_{3}, 500 \mathrm{MHz}\right): 1.49\left(\mathrm{~d}, J=7.32 \mathrm{~Hz}, 1 \mathrm{H}, \mathrm{H}_{1}\right)$, $1.69\left(\mathrm{~d}, J=8.78 \mathrm{~Hz}, 1 \mathrm{H}, \mathrm{H}_{7}\right), 3.25\left(\mathrm{~s}, 2 \mathrm{H}, \mathrm{H}_{2}, \mathrm{H}_{6}\right), 3.41$ (s, $\left.2 \mathrm{H}, \mathrm{H}_{\text {köprü }}\right), 3.77\left(\mathrm{~s}, 3 \mathrm{H}, \mathrm{OCH}_{3}\right), 6.14(\mathrm{~s}, 2 \mathrm{H}, \mathrm{HC}=\mathrm{CH}), 6.84$ (d, $J=8.79 \mathrm{~Hz}, 2 \mathrm{H}, \mathrm{HAr}$ ), 7.68 (d, $J=8.79 \mathrm{~Hz}, 2 \mathrm{H}, \mathrm{HAr}$ ), 8.75 (s, $1 \mathrm{H}, \mathrm{N}=\mathrm{CH})$ ppm. ${ }^{13} \mathrm{C}-\mathrm{NMR}\left(\mathrm{CDCl}_{3}, 125 \mathrm{MHz}\right)$ : $46.1(\mathrm{CH}), 46.2(\mathrm{CH}), 49.6(\mathrm{CH}), 50.0(\mathrm{CH}), 52.1\left(\mathrm{CH}_{2}\right)$, $52.9\left(\mathrm{OCH}_{3}\right), 135.9(2 \mathrm{x}=\mathrm{CH}), 116.2(2 \mathrm{xCAr}), 125.3(\mathrm{Cq})$, $130.1(2 \times C A r), 154.1(\mathrm{~N}=\mathrm{CH}), 169.1(\mathrm{Cq}), 179.2(2 \mathrm{xC}=\mathrm{O})$ ppm. GC-MS (EI, 70eV): $\left(\mathrm{C}_{17} \mathrm{H}_{16} \mathrm{~N}_{2} \mathrm{O}_{3}\right) \mathrm{m} / \mathrm{z}: 296[\mathrm{M}]^{+}$ 
5-(4-Klorofenil)-N-(4-metoksibenziliden)bisiklo[2.2.1] hept-5-en-endo-2,3-dikarboksimid bileşiğinin (Bileşik 4) Sentezi ve Spektral Verileri:

Paladyum (II) asetat [Pd(OAc) $\left.\left.)_{2}, 2.8 \mathrm{mg}, 0.0128 \mathrm{mmol}\right)\right]$ ve trifenilarsin (TPAs, $16,85 \mathrm{mg}, 0.055 \mathrm{mmol}$ ) tartılarak schlenk tüpüne alındı ve $3 \mathrm{~mL}$ susuz DMF içerisinde çözünmesi sağlandı. $15 \mathrm{dk}$ boyunda azot atmosferi altında, $65^{\circ} \mathrm{C}$ sıcaklıkta kompleks oluşumu için karıştırıldı. Reaksiyon karışımına sırasıyla $0.5 \mathrm{mmol}$ Bileşik-3 (148 mg), $0.75 \mathrm{mmol}$ p-kloroiyodobenzen $(179 \mathrm{mg}), 1.75 \mathrm{mmol}$ trietilamin $\left(\mathrm{Et}_{3} \mathrm{~N}\right.$, $0.24 \mathrm{~mL}$ ) ve $1.5 \mathrm{mmol}$ formik asit $(\mathrm{HCOOH}, 0.055 \mathrm{~mL})$ enjektörler yardımıyla ilave edildi. Reaksiyon karışımı bir gece boyunca $65^{\circ} \mathrm{C}$ sıcaklıkta karıştırıldı. Yapılan TLC kontrolleri sonucunda reaksiyon sonlandirıldi. Tuzlu su $(50 \mathrm{~mL})$ ve etil asetat $(50 \mathrm{~mL})$ sisteminden ekstraksiyon yapıld, organik faz ayrılarak $\mathrm{MgSO}_{4}$ üzerinde kurutuldu. Çözücü düşük basınç altında uzaklaştırıldı. Elde edilen ham ürün 1:1 etil asetat $/ n$-hekzan sisteminden kolon kromatografisi yard1mıyla saflaştırıldı. Kolon sonucunda Bileşik-4 beyaz kristaller olarak elde edildi.

Beyaz renkli kristaller, en. $66.1-66.3^{\circ} \mathrm{C}, \mathrm{Rf}: 0.40$ (1:1 etilasetat/n-hekzan), verim \%58. FTIR (ATR): 3013 (aromatik $=\mathrm{C}-\mathrm{H}$ gerilimi), 2970 ve 2839 (alifatik C-H gerilimleri), 1770 ve $1709(\mathrm{C}=\mathrm{O}$ gerilimleri), 1603 ve $1570(\mathrm{C}=\mathrm{N}$, $\mathrm{C}=\mathrm{C}$ gerilimleri), 1514, 1493, 1460, 1422 ve 1375 (alifatik, düzlem içi C-H eğilimleri), 1255 (C-O gerilimi), 1169 (C-O-C gerilimi), 1029 (C-N salınımı), 741 (p-disubstitue aromatik halka düzlem dışı $\mathrm{C}-\mathrm{H}$ eğilimleri) $\mathrm{cm}^{-1} .{ }^{1} \mathrm{H}-\mathrm{NMR}$ $\left(\mathrm{CDCl}_{3}, 500 \mathrm{MHz}\right): 1.58\left(\mathrm{~d}, J=13.76 \mathrm{~Hz}, 1 \mathrm{H}, \mathrm{H}_{10 \mathrm{a}}\right), 1.85$ $\left(\mathrm{m}, 2 \mathrm{H}, \mathrm{H}_{10 \mathrm{~s}}, \mathrm{H}_{9 \mathrm{x}}\right), 1.94\left(\mathrm{dd}, J=14.15 ; 2.93 \mathrm{~Hz}, 1 \mathrm{H}, \mathrm{H}_{9 \mathrm{n}}\right)$, $2.92\left(\mathrm{~d}, J=5.36 \mathrm{~Hz}, 2 \mathrm{H}, \mathrm{H}_{1}, \mathrm{H}_{6}\right), 2.98$ (brds, $\left.1 \mathrm{H}, \mathrm{H}_{7}\right), 3.18-$ $3.22\left(\mathrm{~m}, 1 \mathrm{H}, \mathrm{H}_{2}\right), 3.25\left(\mathrm{dd}, \mathrm{J}=5.37 ; 5.13 \mathrm{~Hz}, 1 \mathrm{H}, \mathrm{H}_{8 \mathrm{n}}\right), 3.86$ $\left(\mathrm{s}, 3 \mathrm{H}, \mathrm{OCH}_{3}\right), 6.94(\mathrm{~d}, J=8.78 \mathrm{~Hz}, 2 \mathrm{H}, \mathrm{HAr}), 7.11$ (d, $J=$ $8.30 \mathrm{~Hz}, 2 \mathrm{H}, \mathrm{HAr}$ ), 7.24 (d, $J=8.30 \mathrm{~Hz}, 2 \mathrm{H}, \mathrm{HAr}$ ), 7.81 (d, $J=8.78 \mathrm{~Hz}, 2 \mathrm{H}, \mathrm{HAr}$ ), 8.99 (s, $1 \mathrm{H}, \mathrm{N}=\mathrm{CH}) \mathrm{ppm} .{ }^{13} \mathrm{C}-\mathrm{NMR}$ $\left(\mathrm{CDCl}_{3}, 125 \mathrm{MHz}\right): 32.6\left(\mathrm{CH}_{2}\right), 39.1(\mathrm{CH}), 40.0(\mathrm{CH}), 41.2$ $(\mathrm{CH}), 46.0(\mathrm{CH}), 46.4(\mathrm{CH}), 46.9\left(\mathrm{CH}_{2}\right), 55.4\left(\mathrm{OCH}_{3}\right), 114.3$ (2xCAr), 120.6 (2xCAr), 125.6 (Cq), 130.1 (2xCAr), 132.0 (2xCAr), $142.86(\mathrm{Cq}) 162.5(\mathrm{Cq}), 154.1(\mathrm{~N}=\mathrm{CH}), 169.1$ (Cq), $174.2(\mathrm{C}=\mathrm{O}), 174.3(\mathrm{C}=\mathrm{O})$ ppm. GC-MS (EI, 70eV): $\left(\mathrm{C}_{23} \mathrm{H}_{21} \mathrm{~N}_{2} \mathrm{O}_{3} \mathrm{Cl}\right) \mathrm{m} / \mathrm{z}: 408[\mathrm{M}]^{+}$

5-(4-Metoksifenil)-N-(4-metoksibenziliden)bisiklo[2.2.1]hept-5-en-endo-2,3-dikarboksimid bileşiğinin (Bileşik 5) Sentezi ve Spektral Verileri:

Paladyum (II) asetat [ $\left.\left.\mathrm{Pd}(\mathrm{OAc})_{2}, 2.8 \mathrm{mg}, 0.0128 \mathrm{mmol}\right)\right]$ ve trifenilarsin (TPAs, $16,85 \mathrm{mg}, 0.055 \mathrm{mmol}$ ) tartılarak schlenk tüpüne alındı ve $3 \mathrm{~mL}$ susuz DMF içerisinde çözünmesi sağlandi. $15 \mathrm{dk}$ boyunda azot atmosferi altında, $65^{\circ} \mathrm{C}$ sıcaklıkta kompleks oluşumu için karıştırıldı. Reaksiyon karışımına sırasıyla $0.5 \mathrm{mmol}$ Bileşik-3 (148 mg), 0.75 mmol p-metoksiiyodobenzen $(175.5 \mathrm{mg}), 1.75 \mathrm{mmol}$ trietilamin $\left(\mathrm{Et}_{3} \mathrm{~N}, 0.24 \mathrm{~mL}\right)$ ve $1.5 \mathrm{mmol}$ formik asit $(\mathrm{HCOOH}$, $0.055 \mathrm{~mL}$ ) enjektörler yardımıyla ilave edildi. Reaksiyon karışımı bir gece boyunca $65^{\circ} \mathrm{C}$ sıcaklıkta karıştırıldı. Yapılan TLC kontrolleri sonucunda reaksiyon sonlandırıldı. Tuzlu su $(50 \mathrm{~mL})$ ve etil asetat $(50 \mathrm{~mL})$ sisteminden ekstraksiyon yapıldı, organik faz ayrılarak $\mathrm{MgSO}_{4}$ üzerinde kurutuldu ve çözücüsü uçuruldu. Çözücü düşük basınç altında uzaklaştırıldı. Elde edilen ham ürün 1:1 etil asetat $/ n$-hekzan sisteminden kolon kromatografisi yardımıyla saflaştırıldı. Kolon sonucunda Bileşik-5 beyaz kristaller olarak elde edildi.

Beyaz renkli kristaller, en. $80.2-81.7^{\circ} \mathrm{C}$, Rf: 0.38 (1:1 etilasetat/n-hekzan), verim \%41. FTIR (ATR): 3015 ve 3013 (aromatik $=\mathrm{C}-\mathrm{H}$ gerilimi), 2985 ve 2841 (alifatik C-H gerilimleri), 1772 ve 1711 ( $\mathrm{C}=\mathrm{O}$ gerilimleri), 1605 ve 1568 $(\mathrm{C}=\mathrm{N}, \mathrm{C}=\mathrm{C}$ gerilimleri), 1515, 1493, 1460, 1421 ve 1381 (alifatik, düzlem içi C-H eğilimleri), 1256 ve 1250 (C-O gerilimi), 1171 (C-O-C gerilimi), 1026 (C-N salınımı), 741 ve 738 (p-disubstitue aromatik halka düzlem dişı C-H eğilimleri) $\mathrm{cm}^{-1} .{ }^{1} \mathrm{H}-\mathrm{NMR}\left(\mathrm{CDCl}_{3}, 500 \mathrm{MHz}\right): 1.61(\mathrm{~d}, J=13.8 \mathrm{~Hz}$, $\left.1 \mathrm{H}, \mathrm{H}_{10 \mathrm{a}}\right), 1.87\left(\mathrm{~m}, 2 \mathrm{H}, \mathrm{H}_{7 \mathrm{~s}}, \mathrm{H}_{9 \mathrm{x}}\right), 1.92(\mathrm{dd}, J=14.15 ; 2.93$ $\left.\mathrm{Hz}, 1 \mathrm{H}, \mathrm{H}_{9 \mathrm{n}}\right), 2.91\left(\mathrm{~d}, J=5.4 \mathrm{~Hz}, 2 \mathrm{H}, \mathrm{H}_{1}, \mathrm{H}_{7}\right), 3.0$ (brds, $1 \mathrm{H}$, $\left.\mathrm{H}_{2}\right), 3.21-3.25\left(\mathrm{~m}, 1 \mathrm{H}, \mathrm{H}_{6}\right), 3.25(\mathrm{dd}, \mathrm{J}=5.37 ; 5.13 \mathrm{~Hz}, 1 \mathrm{H}$, $\left.\mathrm{H}_{8 \mathrm{n}}\right), 3.86\left(\mathrm{~s}, 3 \mathrm{H}, \mathrm{OCH}_{3}\right), 3.88\left(\mathrm{~s}, 3 \mathrm{H}, \mathrm{OCH}_{3}\right), 6.90(\mathrm{~d}, J=$ $8.8 \mathrm{~Hz}, 2 \mathrm{H}, \mathrm{HAr}$ ), 7.10 (d, $J=8.28 \mathrm{~Hz}, 2 \mathrm{H}, \mathrm{HAr}$ ), 7.21 (d, $J=8.28 \mathrm{~Hz}, 2 \mathrm{H}, \mathrm{HAr}$ ), 7.83 (d, $J=8.8 \mathrm{~Hz}, 2 \mathrm{H}, \mathrm{HAr}$ ), 8.99 (s, $1 \mathrm{H}, \mathrm{N}=\mathrm{CH}) \mathrm{ppm} .{ }^{13} \mathrm{C}-\mathrm{NMR}\left(\mathrm{CDCl}_{3}, 125 \mathrm{MHz}\right): 32.7\left(\mathrm{CH}_{2}\right)$, $39.0(\mathrm{CH}), 41.0(\mathrm{CH}), 41.3(\mathrm{CH}), 45.8(\mathrm{CH}), 46.3(\mathrm{CH})$, $46.9\left(\mathrm{CH}_{2}\right), 55.4\left(\mathrm{OCH}_{3}\right), 55.5\left(\mathrm{OCH}_{3}\right), 116.3(2 \times C A r)$, 121.5 (2xCAr), $126.8(\mathrm{Cq}), 130.1(\mathrm{Cq}) 131.1$ (2xCAr), $132.0(2 \times C A r), 159.9(\mathrm{Cq}) 161.5(\mathrm{Cq}), 154.1(\mathrm{~N}=\mathrm{CH}), 174.2$ $(\mathrm{C}=\mathrm{O}), 174.3(\mathrm{C}=\mathrm{O})$ ppm. GC-MS (EI, 70eV): $\left(\mathrm{C}_{24} \mathrm{H}_{24} \mathrm{~N}_{2} \mathrm{O}_{4}\right)$ $\mathrm{m} / \mathrm{z}: 404[\mathrm{M}]^{+}$.

\section{SONUÇ}

Sonuç olarak, bisiklik yapıda schiff bazları sentezlenmiş ve indirgen Heck reaksiyonları kullanılarak türevlendirilmiştir. Sentezlenen bu yeni bileşiklerin yapıları FTIR, 1H-NMR, 13C-NMR ve GC-MS kullanılarak aydınlatılmıştır. Bu sentezlenen yeni bileşiklerin çeşitli kanser hücre hatlarına karşı anti-kanser aktivite göstermesi beklenmektedir. Bir sonraki çalışmada MTT test yöntemi ile bu bileşiklerin anti-kanser aktiviteleri belirlenmesi planlanmaktadır.

\section{TEŞEKKÜR}

$\mathrm{Bu}$ çalışmada desteklerini esirgemeyen rahmetli hocamız Prof.Dr. Nüket ÖCAL'a sonsuz teşekkürlerimi sunarım. 


\section{KAYNAKLAR}

1. Dang, C. V. (2018). Convergence to Cure Cancer through Research. Cancer Res, 78 (1), 3-4.

2. Hait, W. N. (2011). Forty Years of Translational Cancer Research. Cancer Discov, 1 (7), 627-627.

3. Balaraman, S., Nayak, N., Subbiah, M. ve Elango, K. P. (2018). Synthesis and antiviral study of novel 4-(2-(6-amino-4-oxo-4,5-dihydro-1H-pyrrolo[2,3-d]pyrimidin-3-yl)ethyl)benzamide derivatives. Med Chem Res 27 (11-12), 25382546.

4. Gujarati, N. A., Zeng, L. L., Gupta, P., Chen, Z. S. ve Korlipara, V. L. (2017). Design, synthesis and biological evaluation of benzamide and phenyltetrazole derivatives with amide and urea linkers as BCRP inhibitors. Bioorg Med Chem Lett, 27 (20), 4698-4704.

5. Kaur, A., Pathak, D. P., Sharma, V., Narasimhan, B., Sharma, P., Mathur, R. ve Wakode, S. (2018). Synthesis, biological evaluation and docking study of N-(2-(3,4,5-trimethoxybenzyl)benzoxazole-5-yl) benzamide derivatives as selective COX-2 inhibitor and anti-inflammatory agents. Bioorg Chem, 81, 191-202.

6. Lu, K., Cai, L. D., Zhang, X., Wu, G. D., Xu, C. J., Zhao, Y. F. ve Gong, P. (2018). Design, synthesis, and biological evaluation of novel substituted benzamide derivatives bearing a 1,2,3-triazole moiety as potent human dihydroorotate dehydrogenase inhibitors. Bioorg Chem, 76, 528-537.

7. Perin, N., Roskaric, P., Sovic, I., Bocek, I., Starcevic, K., Hranjec, M. ve Vianello, R. (2018). Amino-Substituted Benzamide Derivatives as Promising Antioxidant Agents: A Combined Experimental and Computational Study. Chem Res Toxicol, 31 (9), 974-984.

8. Thirumurugan, K., Lakshmanan, S., Govindaraj, D., Prabu, D. S. D., Ramalakshmi, N. ve Antony, S. A. (2018). Design, synthesis and anti-inflammatory activity of pyrimidine scaffold benzamide derivatives as epidermal growth factor receptor tyrosine kinase inhibitors. J Mol Struct, 1171, 541-550.

9. Vandyck, K., Rombouts, G., Stoops, B., Tahri, A., Vos, A., Verschueren, W., Wu, Y. M., Yang, J. M., Hou, F. L., Huang, B., Vergauwen, K., Dehertogh, P., Berke, J. M. ve Raboisson, P. (2018). Synthesis and Evaluation of N-Phenyl-3-sulfamoyl-benzamide Derivatives as Capsid Assembly Modulators Inhibiting Hepatitis B Virus (HBV). J Med Chem 61 (14), 6247-6260.

10. Wei, M. M., Peng, X., Xing, L., Dai, Y., Huang, R. M., Geng, M. Y., Zhang, A., Ai, J. ve Song, Z. L. (2018). Design, synthesis and biological evaluation of a series of novel 2-benzamide-4-(6-oxy-N-methyl-1-naphthamide)-pyridine derivatives as potent fibroblast growth factor receptor (FGFR) inhibitors. Eur J Med Chem, 154, 9-28.

11. Creaven, B. S., Duff, B., Egan, D. A., Kavanagh, K., Rosair, G., Thangella, V. R. ve Walsh, M. (2010). Anticancer and antifungal activity of copper(II) complexes of
quinolin-2(1H)-one-derived Schiff bases. Inorg Chim Acta, 363 (14), 4048-4058.

12. Ghorab, M. M., Shaaban, M. A., Refaat, H. M., Heiba, H. I. ve Ibrahim, S. S. (2012). Anticancer and radiosensitizing evaluation of some new pyranothiazole-Schiff bases bearing the biologically active sulfonamide moiety. Eur J Med Chem, 53, 403-407.

13. Obeid, A., El-Shekeil, A., Al-Aghbari, S., Al-Shabi, J. (2012). Anticancer, DNA cleavage, and antimicrobial activity studies of some new Schiff-base titanium(IV) complexes. J Coord Chem, 65 (15), 2762-2770.

14. Pignatello, R., Panico, A., Mazzone, P., Pinizzotto, M. R., Garozzo, A. ve Furneri, P. M. (1994). Schiff-Bases of N-Hydroxy-N'-Aminoguanidines as Antiviral, Antibacterial and Anticancer Agents. Eur J Med Chem, 29 (10), 781-785.

15. Shukla, S., Srivastava, R. S., Shrivastava, S. K., Sodhi, A. ve Kumar, P. (2013). Synthesis, characterization, in vitro anticancer activity, and docking of Schiff bases of 4-amino-1,2-naphthoquinone. Med Chem Res, 22 (4), 1604-1617.

16. Sondhi, S. M., Arya, S., Rani, R., Kumar, N. ve Roy, P. (2012). Synthesis, anti-inflammatory and anticancer activity evaluation of some mono - and bis-Schiff's bases. Med Chem Res. 21 (11), 3620-3628.

17. Tabassum, S., Amir, S., Arjmand, F., Pettinari, C., Marchetti, F., Masciocchi, N., Lupidi, G. ve Pettinari, R. (2013). Mixed-ligand $\mathrm{Cu}(\mathrm{II})$-vanillin Schiff base complexes; effect of coligands on their DNA binding, DNA cleavage, SOD mimetic and anticancer activity. Eur J Med Chem, 60, 216-232.

18. Berlinck, R. G. S., Britton, R., Piers, E., Lim, L., Roberge, M., da Rocha, R. M. ve Andersen, R. J. (1998). Granulatimide and isogranulatimide, aromatic alkaloids with G2 checkpoint inhibition activity isolated from the Brazilian ascidian Didemnum granulatum: Structure elucidation and synthesis. J Org Chem, 63 (26), 9850-9856.

19. Lavrard, H., Rodriguez, F. ve Delfourne, E. (2014). Design of granulatimide and isogranulatimide analogues as potential Chk1 inhibitors: Study of amino-platforms for their synthesis. Bioorgan Med Chem, 22 (17), 4961-4967.

20. Loubinoux, B., Gerardin, P., Kunz, W. ve Herzog, J. (1991). Activity of Fumaramidmycin Mimics against Oomycetes. Pestic Sci, 33 (3), 263-269.

21. Moreau, P., Anizon, F., Sancelme, M., Prudhomme, M., Bailly, C., Carrasco, C., Ollier, M., Severe, D., Riou, J. F., Fabbro, D., Meyer, T. ve Aubertin, A. M. (1998). Syntheses and biological evaluation of indolocarbazoles, analogues of rebeccamycin, modified at the imide heterocycle. $J$ Med Chem, 41 (10), 1631-1640.

22. Moreau, P., Anizon, F., Sancelme, M., Prudhomme, M., Severe, D., Riou, J. F., Goossens, J. F., Henichart, J. P., Bailly, C., Labourier, E., Tazzi, J., Fabbro, D., Meyer, T. ve Aubertin, A. M. (1999). Synthesis, mode of action, and biological activities of rebeccamycin bromo derivatives. J Med Chem, 42 (10), 1816-1822. 
23. Browne, S. G. (1960). Cantharidin Poisoning Due to a "Blister Beetle". Br Med J, 2 (5208), 1290-1.

24. Feng, S., Zhu, J., Xia, K., Yu, W., Wang, Y., Wang, J., Li, F., Yang, Z., Yang, X., Liu, B., Tao, H. ve Liang, C. (2018). Cantharidin Inhibits Anti-Apoptotic Bcl-2 Family Proteins and Induces Apoptosis in Human Osteosarcoma Cell Lines MG-63 and MNNG/HOS via Mitochondria-Dependent Pathway. Med Sci Monit, 24, 6742-6749.

25. Liu, Y. P., Li, L., Xu, L., Dai, E. N. ve Chen, W. D. (2018). Cantharidin suppresses cell growth and migration, and activates autophagy in human non-small cell lung cancer cells. Oncol Lett, 15 (5), 6527-6532.

26. Mu, Z. ve Sun, Q. (2018). Cantharidin inhibits melanoma cell proliferation via the miR21mediated PTEN pathway. Mol Med Rep, 18 (5), 4603-4610.

27. Wang, G., Dong, J. ve Deng, L. (2018). Overview of Cantharidin and its Analogues. Curr Med Chem, 25 (17), 2034-2044.

28. Wang, W. J., Wu, M. Y.,Shen, M., Zhi, Q., Liu, Z. Y., Gong, F. R., Tao, M. ve Li, W. (2015). Cantharidin and norcantharidin impair stemness of pancreatic cancer cells by repressing the beta-catenin pathway and strengthen the cytotoxicity of gemcitabine and erlotinib. Int J Oncol, 47 (5), 1912-22.

29. Li, C. C., Yu, F. S., Fan, M. J., Chen, Y. Y., Lien, J. C., Chou, Y. C., Lu, H. F., Tang, N. Y., Peng, S. F., Huang, W. W. ve
Chung, J. G. (2017). Anticancer effects of cantharidin in A431 human skin cancer (Epidermoid carcinoma) cells in vitro and in vivo. Environ Toxicol, 32 (3), 723-738.

30. Gul, M., Kulu, I., Gunkara, O. T. ve Ocal, N. (2013). Reductive Heck Reactions and [3+2] Cycloadditions of Unsaturated N,N'-Bistricyclic Imides. Acta Chim Slov, 60 (1), 87-94.

31. Gunkara, O. T., Kulu, I. ve Ocal, N. (2015). Aryl - and Heteroaryl Substituted Tandospirones as Possible Antidepressant Drugs. Mini-Rev Med Chem, 15 (9), 789-796.

32. Gunkara, O. T., Kulu, I., Ocal, N. ve Kaufmann, D. E. (2010). Synthesis of arylated norbornyl amino acid esters. Monatsh Chem, 141 (11), 1237-1243.

33. Gunkara, O. T. ve Ocal, N. (2015). Hydroarylation Reactions of N-Substituted Tricyclic Imides. Mini-Rev Org Chem, 12 (5), 424-434.

34. Niwayama, S., Cho, H., Zabet-Moghaddam, M. ve Whittlesey, B. R. (2010). Remote exo/endo selectivity in selective monohydrolysis of dialkyl bicyclo[2.2.1] heptane-2,3-dicarboxylate derivatives. J Org Chem, 75 (11), 3775-80.

35. Kas'yan, L. I., Tarabara, I. N., Bondarenko, Y. S., Shishkina, S. V., Shishkin, O. V. ve Musatov, V. I. (2005). Structure and reactivity of bicyclo[2.2.1] hept-2-ene-endo-5, endo-6-dicarboxylic (endic) acid hydrazide. Russ J Org Chem+, 41 (8), 1122-1131. 